\title{
Photosynthetic Rate, Flowering, and Yield Component Alteration in Hazelnut in Response to Different Light Environments
}

\author{
Cheryl R. Hampson ${ }^{1}$ and Anita N. Azarenko ${ }^{2}$ \\ Department of Horticulture, 4017 Agriculture and Life Sciences Building, Oregon State University, \\ Corvallis, OR 97331
}

John R. Potter ${ }^{3}$

Horticultural Crops Research Lab, Agricultural Research Service, U.S. Department of Agriculture, 3420

NW Orchard Avenue, Corvallis, OR 97330

Additional index words. Corylus avellana, fruit set, nut quality, canopy management, gas exchange

\begin{abstract}
In hazelnut (Corylus avellana $\mathrm{L}$.), vigorous vegetative growth and traditional orchard practices that include little or no pruning combine to produce a dense, shady canopy. A study designed to quantify the effect of shade on reproduction and photosynthetic rate in this shade-tolerant species was undertaken to assess whether some degree of pruning might improve productivity. Shade cloth was used to exclude $30 \%, 47 \%, 63 \%, 73 \%$, or $92 \%$ of ambient sunlight from whole 'Ennis' and 'Barcelona' trees from mid-May until harvest. Photosynthetic light response curves were obtained for leaves that had developed in full sunlight, deep inside the canopy of unshaded trees, or in $92 \%$ shade. Light-saturated net photosynthetic rates were $12.0,6.1$, and $9.3 \mu \mathrm{mol} \cdot \mathrm{m}^{-2} \cdot \mathrm{s}^{-1}$ of $\mathrm{CO}_{2}$ and dark respiration rates were $2.0,1.1$, and 0.7 $\mu \mathrm{mol} \cdot \mathrm{m}^{-2} \cdot \mathrm{s}^{-1}$ of $\mathrm{CO}_{2}$, respectively, for the three light regimes. Light-saturated photosynthetic rates of leaves from $30 \%$ or $63 \%$ shade differed little from the control ( $0 \%$ shade). Area per leaf increased by $49 \%$ and chlorophyll concentration (dry weight basis) by $157 \%$ as shading increased from $0 \%$ to $92 \%$. Shading to $92 \%$ reduced specific leaf weight $(68 \%)$, stomatal density $(30 \%)$, light compensation point $(69 \%)$, and dark respiration rate $(63 \%)$ compared to controls. Female inflorescence density declined by about one-third and male inflorescence density by $64 \%$ to $74 \%$ in the most heavily shaded trees of both cultivars compared to controls. Shade was more detrimental to yield than flowering: yield per tree dropped by $>80 \%$, from 2.9 to $3.4 \mathrm{~kg}$ in full sun to 0.6 to $0.9 \mathrm{~kg}$ in $92 \%$ shade. Shade reduced yield primarily by decreasing nut number and secondarily by decreasing nut size. The incidence of several kernel defects increased as shade increased. Therefore, hazelnut leaves showed considerable capacity to adapt structurally and functionally to shade, but improving light penetration into the canopy would probably increase orchard productivity.
\end{abstract}

Hazelnut (Corylus avellana) occurs chiefly as an understory tree in its native habitat, the forests of Europe (Kull and Niinemets, 1993). This species is also grown commercially as an orchard crop in parts of Mediterranean Europe and the United States, including the Willamette Valley of Oregon, where plantings have recently increased to about 12,000 ha (U.S. Dept. of Agriculture, 1993).

Hazelnut is not a high-yielding crop. Westwood (1993) notes that the maximum expected yield for hazelnuts is $4.5 \mathrm{t} \cdot \mathrm{ha}^{-1}$, half that of walnut. Actual yield is often substantially lower and below that of most other nut crops (U.S. Dept. of Agriculture, 1993). Hazelnut yields plateau after 10 to 12 years (Jona, 1985), although the trees continue to enlarge.

One reason for low productivity could be insufficient light infiltration into the canopy. Attenuation of photosynthetically active radiation (PAR) is very rapid with depth in the dense canopies of hazelnut orchards, which are currently pruned minimally or not at all. Analysis of fisheye photographs in 17- and 32-

Received for publication 22 Dec. 1995. Accepted for publication 27 June 1996. Oregon Agriculture Experiment Station paper number 10962. This paper is a portion of the PhD thesis of C.R.H. We thank Rebecca McCluskey, Juanita Rasmussen, and the Oregon State Univ. Horticulture farm crews for their excellent technical assistance and Caryn Thompson for statistical advice. Partial funding from the Oregon Hazelnut Commission is gratefully acknowledged. The cost of publishing this paper was defrayed in part by the payment of page charges. Under postal regulations, this paper therefore must be hereby marked advertisement solely to indicate this fact.

${ }^{1}$ Current address: Agriculture and Agri-Food Canada, Research Centre, Summerland, B.C., Canada VOH $1 \mathrm{ZO}$.

${ }^{2}$ Associate professor.

${ }^{3}$ Research plant physiologist. year-old orchards revealed that canopy closure occurs at the end of May; thereafter, only about $20 \%$ sky is visible in the hemispheric photographs (A. Azarenko and J. Olsen, unpublished data). Quantum sensor readings show that $<30 \mu \mathrm{mol} \cdot \mathrm{m}^{-2} \cdot \mathrm{s}^{-1}$ of incident photosynthetic photon flux (PPF) penetrates to the base of the canopy. Using the leaf area to dry weight ratio from a large subsample (7 to $10 \mathrm{~m}^{2}$ ) of leaves, we estimated the leaf area density (leaf area per unit ground area under the canopy) and leaf area index (leaf area per unit ground area allotted to tree, including alleyways) of 10year-old hazelnut trees to be 7.6 and 6.1, respectively.

Insufficient light infiltration reduces flower bud formation, fruit set, and fruit quality in most orchard crops (Jackson and Palmer, 1977; Snelgar et al., 1992). Minimum light requirements for adequate fruit size, return bloom, and fruit color have been established in apple (Faust, 1989). Shade also decreases nut size and return bloom in walnut (Ryugo et al., 1980). Canopy management to manipulate light penetration is now a routine management practice for fruit crops and has raised productivity, stabilized yield, and improved fruit quality.

Knowledge of how much shade can be tolerated is an essential prerequisite to canopy management. Shade decreases reproductive potential directly (flowering, fruit set, and fruit size) and indirectly by curtailing the vegetative growth necessary to support reproduction. Kull and Niinemets (1993) note that, although hazelnut may grow in full sun in clearings, it is chiefly found in the shade. One might therefore expect hazelnut to be shade-tolerant, but Jona (1985) noted that well-illuminated branches bear from 1.5 to 3 times more female inflorescences than shaded ones. Insufficient light infiltration, producing conditions of excessive shade 
within the canopy, may therefore be a serious production concern in hazelnut.

No information is available in the literature regarding the effect of insufficient light on hazelnut productivity. Information on the photosynthetic rate of hazelnut is also very limited. Previous studies (Harbinson and Woodward, 1984; Schulze and Küppers, 1979) do not provide estimates of the photosynthetic rates of fieldgrown leaves at typical outdoor irradiances or document the plant's photosynthetic response to low-light environments.

Our objective was to quantify the effect of shade (defined here as exclusion of PAR) on hazelnut flowering, yield, nut quality, and photosynthetic rate. We excluded light from whole trees in the field, choosing a range of shade regimes representative of natural canopies, and imposing shade in May, to mimic the estimated time of natural canopy closure. The broader goal of this research was to obtain concrete baseline information on which to base any future canopy management practices.

\section{Materials and Methods}

Plant material. Self-rooted 'Ennis' hazelnut trees were enclosed in cages $(2.4 \times 2.4 \times 2.4 \mathrm{~m})$ covered with black polypropylene shade cloth (A.M. Leonard, Piqua, Ohio) that excluded 30\%, $47 \%, 63 \%, 73 \%$, or $92 \%$ of ambient light. The shade cloth extended to the base of the canopy. The trees were planted in 1987 at the Oregon State Univ. Vegetable Crops Research farm near Corvallis, Ore., on a $3.1 \times 6.1-\mathrm{m}$ spacing in north-south rows, with 'Butler' pollenizers every sixth tree in every third row. Control trees were unshaded ( $0 \%$ shade). Four replicate trees per shade regime were designated in a completely randomized design. The PAR at 27 points within the control trees was measured once monthly (May to August 1992 inclusive) on cloudless days between $10 \mathrm{Am}$ and $3 \mathrm{PM}$ using a point quantum sensor (LI-COR, Lincoln, Neb.). PAR was measured at nine intersection points on a grid set up in the canopy at each of three different heights (1.5, 2.1 , and $2.7 \mathrm{~m}$ from the ground).

The 'Ennis' trees were shaded for two consecutive growing seasons. Shade cloth was put up at the end of May 1991 and removed in late September just before harvest. The same treatments were applied to the same trees in 1992, except that shading started 7 to 12 May and 0.6-m extensions were added to the cages to accommodate tree growth. In 1993, the same treatments were applied to 4-year-old 'Barcelona' trees in a commercial orchard near Millersburg, Ore. The trees were planted on a $2.7 \times 5.5-\mathrm{m}$ spacing in east-west rows, with a mixture of different pollenizers in solid rows every tenth row. Shade cloth was put in place in midMay and removed after harvest. Only 1 year of data was taken on 'Barcelona.'

Quantum sensor readings taken from inside the shade cloth at the top of the cages indicated that the PAR exclusion was within $2 \%$ of the nominal value. Air temperature inside trees in the $92 \%$ shade treatment deviated from that in unshaded trees by about $1^{\circ} \mathrm{C}$ or less (Hampson, 1995). Shade cloth does not change the spectral distribution of the PAR transmitted (Lee, 1985).

Leaf characteristics. Mean leaf size, dry weight per unit area [specific leaf weight (SLW)], and chlorophyll content were determined on 13 July 1992 on a subsample of five midshoot leaves per tree from the uppermost part of the canopy on the west side. Leaf area was measured with a leaf area meter (LI-3000 or model 3100; LI-COR). Four discs ( $8 \mathrm{~mm}$ in diameter) were cut with a cork borer from interveinal areas of each leaf for chlorophyll extraction, and the rest of the leaf was dried at $65^{\circ} \mathrm{C}$ for $72 \mathrm{~h}$. Leaf areas were corrected for the removal of the discs before calculating SLW.
Leaf discs were placed in $5 \mathrm{~mL}$ of 80 acetone : 20 water (by volume), vortexed for a few seconds, covered, and extracted in the dark for $48 \mathrm{~h}$ at room temperature (Proctor, 1981). Samples were then vortexed briefly, and the absorbance at 645 and $663 \mathrm{~nm}$ was recorded. None of the samples was turbid, and filtration did not change the absorbance readings. Chlorophyll concentration per unit area and chlorophyll $\mathrm{a} / \mathrm{b}$ ratio were calculated using published formulae (Arnon, 1949). Chlorophyll per unit dry weight was calculated using the SLW obtained for the same leaf.

Stomata were counted in August 1991 on five midshoot leaves from the upper canopy of each tree. An interveinal area close to the midvein on the distal portion of the leaf was painted with clear nailpolish. After it dried, the polish was peeled off and mounted on a slide. Stomata were counted (three fields per peel) and mean stomatal frequency was calculated.

Flowering and yield. All nuts were hand-harvested after nut fall to evaluate yield and quality. Trunk diameters were measured in January, and yield efficiency was obtained by dividing yield (kg/ tree) by trunk cross-sectional area. Random samples of 100 nuts per tree were weighed and then cracked out to evaluate kernel weight and defects. Defects included blanks (nuts without kernels), moldy, shrivelled, or poorly filled kernels and miscellaneous defects. The miscellaneous category included nuts with filbertworms [Olethreutidae: Melissopus latiferreanus (Walsingham)], brown stain, rancid nuts, double kernels, and black tips. The percentage kernel was corrected for the incidence of blanks as follows: percentage kernel $=[$ kernel weight $/$ (nut weight - weight of blanks)] $\times 100$.

Four large branches per tree in different compass directions were flagged after leaf fall and before bloom for 'Ennis' in 1992 and 'Barcelona' in 1993. Flower density for male and female inflorescences was recorded at bloom (January to February) as the number of nodes bearing an inflorescence $/ \mathrm{cm}^{2}$ branch crosssectional area (BCSA). BCSA was measured at the base of the 3year-old wood. In late August before nut fall, clusters on the marked branches were harvested to obtain nut set (number of nut clusters/number of nodes bearing female inflorescences) and nut density (number of nuts $/ \mathrm{cm}^{2}$ BCSA). The mean of the four branches was used in regression analysis. For 'Barcelona', the number of nuts per cluster was also noted.

Photosynthesis measurements. All photosynthesis measurements were done in the laboratory between 22 June and 9 July 1992 on cut shoots from well-watered, vigorously growing trees. Complete light response curves were determined on 22 June to 3 July for leaves from trees in full sun and $92 \%$ shade and leaves on 1year-old shoots growing deep inside the canopy of unshaded (control) trees (primarily watersprouts). Light-saturated net photosynthetic rates $\left(\mathrm{P}_{\max }\right)$, measured at 1000 to $1200 \mu \mathrm{mol} \cdot \mathrm{m}^{-2} \cdot \mathrm{s}^{-1}$ of PAR, were also obtained for $0 \%, 30 \%$ and $63 \%$ shade treatments on 7 to 9 July 1992. Due to the scarcity of new shoots in $92 \%$ shade, $\mathrm{P}_{\max }$ was taken from the readings done for the light response curves for this treatment.

Shoots (about $1 \mathrm{~m}$ ) from the top of the canopy on the west side were cut before dawn, immediately recut under water, and brought to the laboratory. The shoots were placed in flasks of water under two 1000-W high-pressure sodium lamps spaced $70 \mathrm{~cm}$ apart, using $5 \mathrm{~cm}$ of water to absorb infrared radiation. PPF for the light response curves was decreased stepwise by raising and lowering the shoots and by neutral density filters. Leaf gas exchange was measured at eight different irradiances from 0 to $1800 \mu \mathrm{mol} \cdot \mathrm{m}^{-2} \cdot \mathrm{s}^{-1}$ of PAR, about every $300 \mu \mathrm{mol} \cdot \mathrm{m}^{-2} \cdot \mathrm{s}^{-1}$. The shoots were equilibrated at each light level for at least $45 \mathrm{~min}$ before measuring began. Gas exchange was measured on the two most recent fully 
expanded leaves with a portable photosynthesis system (LI-6200; LI-COR) equipped with a 250-mL cuvette. The boundary layer conductance was estimated to be $1.6 \mathrm{~mol} \cdot \mathrm{m}^{-2} \cdot \mathrm{s}^{-1}$ from a filter paper model. Dark respiration rate $\left(\mathrm{R}_{\mathrm{d}}\right)$ was obtained after $\geq 1 \mathrm{~h}$ without light. Complete light response curves were obtained for individual leaves. Leaf areas and dry weights were then determined.

We minimized changes in $\mathrm{CO}_{2}$ concentration, relative humidity, and air temperature as follows: 1) by manual adjustment to minimize humidity change during measurements, 2 ) by completing measurements quickly ( 30 to $60 \mathrm{~s}$ ), and 3 ) by working in an airconditioned laboratory (air temperature $25 \pm 3^{\circ} \mathrm{C}$, relative humidity $48 \% \pm 3 \%, \mathrm{CO}_{2}$ at $365 \pm 5 \mu \mathrm{mol} \cdot \mathrm{mol}^{-1}$ ). Schulze and Küppers (1979) reported that the optimum temperature for photosynthesis in hazelnut is 25 to $28^{\circ} \mathrm{C}$.

Statistical analysis. PC-SAS (versions 6.03 and 6.04, SAS Institute, Cary, N.C.) was used for all analyses. Variables were regressed against percent shade, with the SAS general linear model (GLM) procedure, using the lackofit utility to determine the appropriate order of the equation. Residuals were checked for

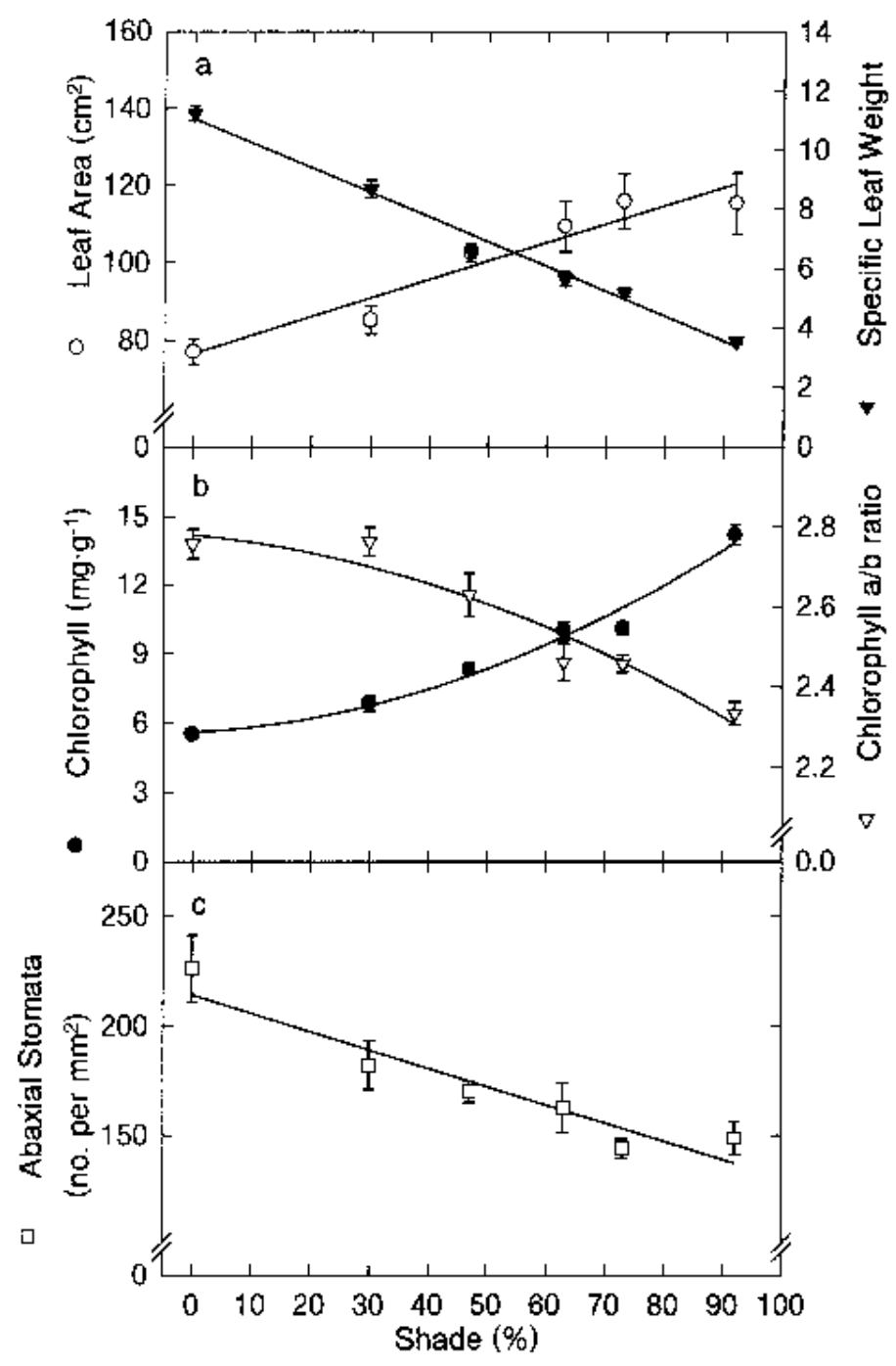

Fig. 1. Relationship between shade and (a) leaf area and specific leaf weight (b) chlorophyll concentration and chlorophyll a/b ratio (c) abaxial stomatal density. Vertical bars indicate standard errors. Regression equations were as follows, where $\mathrm{x}=$ percent shade: leaf area $\left(\mathrm{cm}^{2}\right)=76.44+0.48 \mathrm{x}, r^{2}=0.65^{* * *} ; \mathrm{SLW}\left(\mathrm{mg} \cdot \mathrm{cm}^{-2}\right)$ $=10.76-0.081 \mathrm{x}, r^{2}=0.86^{* * *} ;$ chlorophyll concentration $\left(\mathrm{mg} \cdot \mathrm{g}^{-1}\right.$ dry weight of leaf $)$ $=5.76+0.013 \mathrm{x}+0.00084 \mathrm{x}^{2}, r^{2}=0.77^{* * * *} ;$ chlorophyll $\mathrm{a} / \mathrm{b}$ ratio $2.78-0.0014 \mathrm{x}-$ $0.000040 \mathrm{x}^{2}, r^{2}=0.44^{* *} ;$ stomatal number $/ \mathrm{mm}^{2}=214-0.83 \mathrm{x}, r^{2}=0.64^{* * * *}$. normality and were found to be normally distributed. For leaf variables with subsampling, a nested ANOVA was first performed to check for significant differences among trees within a treatment. If found, the regression was done on tree means. Otherwise, the data were pooled. Tree means were used for leaf area and stomatal density regressions. Values for $\mathrm{R}_{\mathrm{d}}$, light compensation point, quantum efficiency, and $\mathrm{P}_{\max }$ were compared with univariate ANOVA using the GLM procedure.

The photosynthetic light-response curves were fit to a negative exponential model by three-parameter nonlinear regression analysis using the SAS procedure NLIN with the Marquardt fitting option. The model used was based on the MacArthur-Wilson equilibrium equations as described by Campbell et al. (1992), except that a term was added to allow for a nonzero y-intercept, as $R_{d}$ was expected to be negative. Data were fitted to the following negative exponential equation:

$\mathrm{P}_{\mathrm{n}}=\mathrm{R}_{\mathrm{d}}+\mathrm{S}\left(1-e^{-\mathrm{G} \times \mathrm{PPF}}\right)$

where $\mathrm{P}_{\mathrm{n}}=$ net photosynthetic rate, $\mathrm{R}_{\mathrm{d}}=$ dark respiration rate, $\mathrm{S}=$ asymptotic maximum, $e=$ base of natural logarithms, $\mathrm{G}=$ rate of approach to the maximum, and PPF = photosynthetic photon flux.

A curve was fit to the data from each separate leaf, and another curve was fit to the data for all leaves within a given shade treatment. Pseudo- $r^{2}$ values (determined for each model by dividing the regression sum of squares by the total uncorrected sum of E squares) were used to assess goodness of fit, following the example Sof Campbell et al. (1992).

An estimate of $\mathrm{R}_{\mathrm{d}}$ was immediately available, while estimates of other coefficients for the light response curve were calculated from the fitted models for each leaf as follows:

1) Light compensation point, the $x$-intercept of the light response curve, was obtained by setting $\mathrm{P}_{\mathrm{n}}=0$ and solving for PPF.

Light compensation point $\left.=-\ln \left(1+\mathrm{R}_{\mathrm{d}} / \mathrm{S}\right)\right) / \mathrm{G}$

2) Quantum efficiency (mol $\mathrm{CO}_{2}$ fixed/mol quanta absorbed) corresponds to the initial slope of the curve and was estimated by taking the first derivative of $\mathrm{P}_{n}$ with respect to $\mathrm{PPF}$ at $\mathrm{PPF}=0$.

Quantum efficiency $=\mathrm{GS} e^{-\mathrm{G} \times 0}=\mathrm{GS}$

3) The light-saturated rate of photosynthesis $\left(P_{\max }\right)=S+R_{d} \cdot P_{\max }$ is not equal to $S$ because the curve has been shifted downward with respect to the $y$-axis by the addition of the term $R_{d}$ to the model.

\section{Results and Discussion}

Leaf characteristics. Hazelnut leaves demonstrated considerable phenotypic plasticity in several leaf characteristics associated with adaptation to shade. Individual leaf area increased by $50 \%$ with increasing shade (Fig. 1a). Leaves were as large as $183 \mathrm{~cm}^{2}$ under $92 \%$ shade. We found no previous reports on hazelnut of leaf size changes in the shade. Peach leaves were, on average, $20 \%$ larger in $91 \%$ shade than in full sun (Kappel and Flore, 1983). In contrast, Ryugo et al. (1980) reported a $20 \%$ reduction in mean leaf size on shaded compared to sunlit spurs of walnut.

The SLW of hazelnut leaves ranged from 2.9 to $13.1 \mathrm{mg} \cdot \mathrm{cm}^{-2}$ in different light regimes (Fig. 1a). The shade cloth was effective at mimicking natural shade in this respect, for Kull and Niinemets (1993) reported a similar range for hazelnut trees growing in the Estonian forest understory.

Shading also altered leaf chlorophyll concentration and chlorophyll a/b ratio. In $92 \%$ shade, mean chlorophyll concentration was $157 \%$ higher on a dry weight basis than in full sun (Fig. 1b). Shade effects on chlorophyll concentration have been documented in 


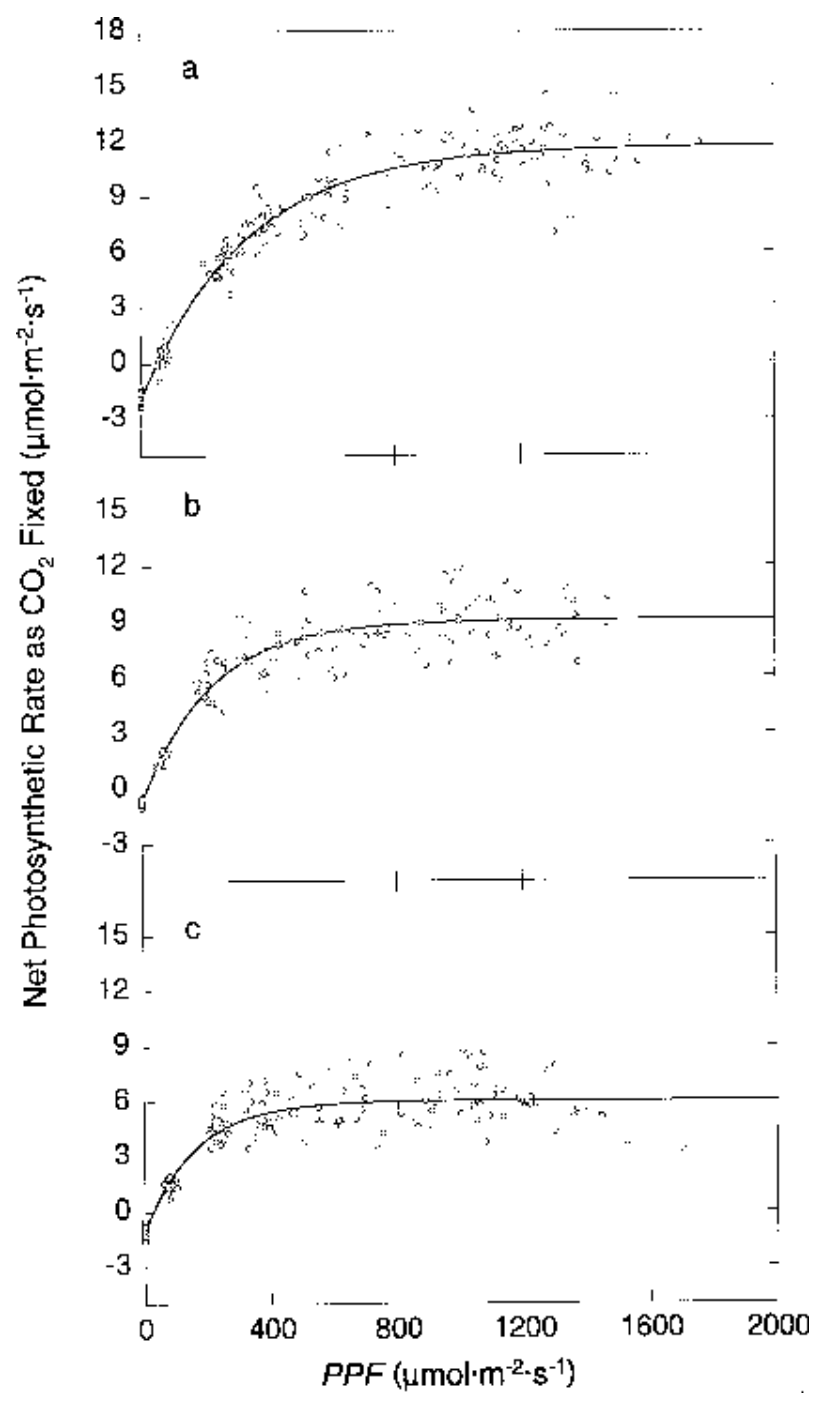

Fig. 2. Scatter plots of observed net photosynthetic rates and curves for equations fitted to the negative exponential model for leaves grown (a) in full sun (b) $92 \%$ shade (c) inside the canopy of unshaded trees. Equations are $\mathrm{P}_{\mathrm{n}}=-1.98+13.75\left(1-e^{-0.00299 \times \mathrm{PPF}}\right)$ for control leaves, $\mathrm{P}_{\mathrm{n}}=-0.74+9.82(1-$ $\left.e^{-0.00466 \times \mathrm{PPF}}\right)$ for leaves in $92 \%$ shade, and $\mathrm{P}_{\mathrm{n}}=-1.09+7.11\left(1-e^{-0.00625 \times \mathrm{PPF}}\right)$ for interior leaves. PPF $=$ photosynthetic photon flux.

other species (Kappel and Flore, 1983; Logan, 1970; Ryugo et al., 1980). Chlorophyll a/b ratio decreased about $18 \%$ between the two most extreme treatments (Fig. 1b), but in absolute terms the change was small. Such changes are considered to be an adaptation to shade (Boardman, 1977).

Stomata were absent on the adaxial leaf surface. Mean stomatal frequency on the abaxial surface was about $226 / \mathrm{mm}^{2}$ in full sun and decreased by about one-third in deep shade (Fig. 1c). Harbinson and Woodward (1984) reported a frequency of only $155 / \mathrm{mm}^{2}$ in hazelnut leaves growing in full sun, and it was unaffected by shade. Abaxial stomatal frequencies are higher in pistachio (Lin et al., 1984) than hazelnut.

Light response curves. The negative exponential model provided excellent fit for the observed photosynthetic light response curves, judging by the proportion of variance associated with the model. Pseudo- $r^{2}$ values exceeded 0.98 for all individual-leaf curves. For the combined data, pseudo- $r^{2}$ values for the model were 0.96 for interior leaves and 0.98 for control leaves and leaves in $92 \%$ shade.

Light above 800 to $1000 \mu \mathrm{mol} \cdot \mathrm{m}^{-2} \cdot \mathrm{s}^{-1}$ of PAR saturated the photosynthetic response of most control leaves (Fig. 2a). This represents about $40 \%$ to $50 \%$ full sun, if full sun is assumed to be $2000 \mu \mathrm{mol} \cdot \mathrm{m}^{-2} \cdot \mathrm{s}^{-1}$ of PAR (Nobel, 1983). Shade-grown leaves saturated at lower PPF (400 to $600 \mu \mathrm{mol} \cdot \mathrm{m}^{-2} \cdot \mathrm{s}^{-1}$ for $92 \%$ shade and 300 to $500 \mu \mathrm{mol} \cdot \mathrm{m}^{-2} \cdot \mathrm{s}^{-1}$ for interior leaves; Fig. $2 \mathrm{~b}$ and $\mathrm{c}$ ). Saturating PPF for leaves from the control and $92 \%$ shade treatments correspond quite closely with those for unshaded and shaded peach (Kappel and Flore, 1983). The PPF needed to saturate photosynthesis in sun-grown leaves is also similar for almond (DeJong, 1983; Higgins et al., 1992). Pecan, walnut, and yellow birch saturate at lower irradiances (Crews et al., 1980; Logan, 1970; Tombesi et al., 1983).

The $\mathrm{P}_{\max }$ values obtained from the fitted curves for the individual-leaf data differed among treatments (Table 1). $\mathrm{P}_{\max }$ for hazelnut leaves grown in full sun was lower than in almond (DeJong, 1983) and pistachio (Lin et al., 1984), similar to walnut (Tombesi et al., 1983), and higher than pecan (Crews et al., 1980). As for other Betulaceae species, the $\mathrm{P}_{\max }$ of red alder was lower (Pezeshki and Hinckley, 1982), while various species of birch ranged from 7 to $16 \mu \mathrm{mol} \cdot \mathrm{m}^{-2} \cdot \mathrm{s}^{-1}$ of $\mathrm{CO}_{2}$ (Logan, 1970; Ranney et al., 1991).

The $\mathrm{P}_{\mathrm{n}}$ of hazelnut at PPF below light saturation agrees well with the limited information already published. Harbinson and Woodward (1984) reported the $\mathrm{P}_{\mathrm{n}}$ of outdoor plants, measured at PPF of $230 \mu \mathrm{mol} \cdot \mathrm{m}^{-2} \cdot \mathrm{s}^{-1}$, to be about $7 \mu \mathrm{mol} \cdot \mathrm{m}^{-2} \cdot \mathrm{s}^{-1}$ of $\mathrm{CO}_{2}$, comparable to leaves here (Fig. 2a). The $\mathrm{P}_{\max }$ for shade leaves (Fig. $2 \mathrm{~b}$ and $\mathrm{c}$ ) was similar to that for leaves of potted trees grown at PAR of about $600 \mu \mathrm{mol} \cdot \mathrm{m}^{-2} \cdot \mathrm{s}^{-1}$ (Schulze and Küppers, 1979; Turner et al., 1984).

Relative to full-sun controls, $\mathrm{P}_{\max }$ was reduced by about $50 \%$ in interior leaves on unshaded trees but only about $23 \%$ for peripheral leaves in the $92 \%$ shade treatment (Table 1). Interior leaves were probably growing in more than $92 \%$ shade. Point light readings with a quantum sensor in control trees were bimodally distributed due to sunflecks and thus highly variable (Table 2 ). In the absence

Table 1. Calculated values for photosynthetic characteristics of hazelnut leaves grown in full sun, inside the canopy, or in $92 \%$ shade $^{\mathrm{Z}}$.

\begin{tabular}{|c|c|c|c|c|c|}
\hline $\begin{array}{l}\text { Source of } \\
\text { leaves }\end{array}$ & $\mathrm{n}$ & $\begin{array}{c}\text { Max } \\
\text { photosynthetic } \\
\text { rate as } \mathrm{CO}_{2} \\
\text { fixed } \\
\left(\mu \mathrm{mol} \cdot \mathrm{m}^{-2} \cdot \mathrm{s}^{-1}\right)\end{array}$ & $\begin{array}{c}\text { Light }(\mathrm{PPF}) \\
\text { compensation } \\
\text { point } \\
\left(\mu \mathrm{mol} \cdot \mathrm{m}^{-2} \cdot \mathrm{s}^{-1}\right)\end{array}$ & $\begin{array}{c}\text { Dark } \\
\text { respiration } \\
\text { rate as } \mathrm{CO}_{2} \\
\text { respired } \\
\left(\mu \mathrm{mol} \cdot \mathrm{m}^{-2} \cdot \mathrm{s}^{-1}\right)\end{array}$ & $\begin{array}{c}\text { Quantum } \\
\text { efficiency } \\
\text { (as } \mathrm{CO}_{2} / \\
\text { quantum) }\end{array}$ \\
\hline Full sun & 22 & $12.0 \mathrm{a}$ & $52 \mathrm{a}$ & $2.0 \mathrm{a}$ & 0.041 \\
\hline $92 \%$ Shade & 18 & $9.3 \mathrm{~b}$ & $16 \mathrm{c}$ & $0.7 \mathrm{~b}$ & 0.045 \\
\hline Interior & 19 & $6.1 \mathrm{c}$ & $27 \mathrm{~b}$ & $1.1 \mathrm{~b}$ & 0.043 \\
\hline
\end{tabular}

${ }^{\mathrm{z}}$ Mean separation within columns by Tukey's studentized range (HSD) test ( $\alpha=0.05$ ). Means followed by the same letter are not significantly different. 
Table 2. Light readings recorded in July at different compass points and heights in unshaded 'Ennis' hazelnut canopies. Quantum sensor (PAR) measurements are expressed as percentage of full-sun readings. Values are shown only for two of four replicate trees.

\begin{tabular}{|c|c|c|c|c|c|c|}
\hline \multirow{4}{*}{$\begin{array}{l}\text { Compass } \\
\text { direction } \\
\text { Northwest }\end{array}$} & \multicolumn{6}{|c|}{ Percent full sun } \\
\hline & \multicolumn{6}{|c|}{ Ht above ground (m) } \\
\hline & \multicolumn{2}{|c|}{2.7} & \multicolumn{2}{|c|}{2.1} & \multicolumn{2}{|c|}{1.5} \\
\hline & 2.8 & 5.8 & 0.7 & 1.7 & 0.3 & 0.8 \\
\hline North & 96.4 & 1.3 & 3.8 & 3.0 & 0.7 & 1.5 \\
\hline Northeast & 96.7 & 1.7 & 0.4 & 3.2 & 0.4 & 0.3 \\
\hline West & 2.7 & 99.9 & 1.5 & 89.8 & 0.5 & 2.5 \\
\hline Center & 4.0 & 85.2 & 1.9 & 3.0 & 0.5 & 1.6 \\
\hline East & 5.9 & 4.2 & 1.8 & 1.1 & 0.7 & 1.0 \\
\hline Southwest & 95.4 & 93.1 & 87.6 & 1.0 & 0.8 & 0.5 \\
\hline South & 95.1 & 4.6 & 3.1 & 0.3 & 0.6 & 0.2 \\
\hline Southeast & 93.9 & 86.2 & 0.4 & 0.5 & 0.2 & 0.3 \\
\hline
\end{tabular}

of sunflecks, midday PAR at about $0.6 \mathrm{~m}$ below the top of the canopy on a $3.3 \mathrm{~m}$ tree was $\leq 5 \%$ to $10 \%$ of full-sun readings by June and $<5 \%$ by July (Table 2 ). Midday PAR readings dropped to $\leq 1 \%$ to $2 \%$ full sun deeper in the canopy in June and later. Natural shade would also be enriched in far-red wavelengths. Other investigators, nevertheless, obtained greater reductions in $\mathrm{P}_{\max }$ for leaves that developed under shade cloth. The $\mathrm{P}_{\max }$ of yellow birch leaves in $87 \%$ shade and peach leaves in $91 \%$ shade was about $55 \%$ of the $\mathrm{P}_{\text {max }}$ in full sun (Logan, 1970; Kappel and Flore, 1983).

The ability of shade-grown leaves to attain high $\mathrm{P}_{\max }$ at high irradiances was surprising, but was consistently observed. Measured photosynthetic rates at light saturation for leaves in four shade treatments are shown in Fig. 3. Leaves that developed in full sun appeared paler green than leaves from other treatments and were puckered along the major veins. Perhaps full sun imposes mild water stress or photoinhibition on hazelnut trees. A quadratic model was fitted to the observed changes in $\mathrm{P}_{\max }$ with shade during leaf development (Fig. 3), but it did not explain much of the observed variation $\left(r^{2}=0.36\right)$.

A high potential $\mathrm{P}_{\max }$ obviously will not benefit a plant grown in continuous shade. Although the trees in $92 \%$ shade for 2 consecutive years showed an impressive ability to continue initiating flower buds and yielding nuts, vegetative vigor declined notably; many buds and small branches inside the canopy died by the end of the study, and the trees had minimal or no trunk growth increments. The lack of vegetative vigor agrees with the observation that this species rarely occupies habitats with $>90 \%$ shade (Kull and Niinemets, 1993).

Higgins et al. (1992) reported light compensation points of 28 to 67 $\mu \mathrm{mol} \cdot \mathrm{m}^{-2} \cdot \mathrm{s}^{-1}$ for various fruit and nut crops. The estimated light compensation point was in this range for sungrown hazelnut leaves but was lower in shade-grown leaves (Table 1).

$\mathrm{R}_{\mathrm{d}}$ for true shade plants is usually 0.06 to $0.16 \mu \mathrm{mol} \cdot \mathrm{m}^{-2} \cdot \mathrm{s}^{-1}$ of $\mathrm{CO}_{2} \mathrm{com}-$ pared to 0.67 to $1.33 \mu \mathrm{mol} \cdot \mathrm{m}^{-2} \cdot \mathrm{s}^{-1}$ for sun plants (Boardman, 1977). As expected for a facultative species, hazelnut falls clearly into the sun plant category (Table 1 ). $\mathrm{R}_{\mathrm{d}}$ rates lower than hazelnut have been reported for many fruit and forest trees (Bassman and Zwier, 1991; Logan, 1970; Marini 1986).

Jackson (1980) noted that sun plants grown in the shade showed reduced $\mathrm{P}_{\max }, \mathrm{R}_{\mathrm{d}}$ and light compensation point, but their quantum efficiency remained unchanged. Quantum efficiencies for hazelnut leaves in the three treatments did not differ (Table 1) and correspond to about $23 \mathrm{~mol}$ quanta/mol $\mathrm{CO}_{2}$ fixed, higher than Harbinson and Woodward's (1984) estimate. Quantum requirements (mol quanta/mol $\mathrm{CO}_{2}$ absorbed) reported for other woody plants include: pome fruit species, 32 to 40; almond, about 17 (Higgins et al., 1992); and cottonwood, 20 to 22 (Bassman and Zwier, 1991). Hazelnut may, therefore, have a lower quantum requirement than pome fruit species, implying that it may be more efficient in low light.

Among horticultural tree crops, hazelnut is therefore moderately efficient at photosynthesis when grown in full sunlight in terms of its $\mathrm{P}_{\max }$, light compensation point, and quantum requirement. In these experiments, shade-grown hazelnut displayed substantial plasticity in morphological and physiological leaf characteristics associated with shade tolerance, while undergoing remarkably little reduction in light-saturated photosynthetic rates. These abilities would maximize the efficiency of light capture at low irradiance without sacrificing the capability to respond to direct sunlight if it became available. In view of hazelnut's evolutionary success as an understory species, such adaptability is not surprising. Of course, potential $\mathrm{P}_{\max }$ is not important if the leaf is in continuous shade, because it would never be light-saturated. In a natural environment, such as a forest understory, or interior and lower parts of a sunlit canopy, sun flecks and low-angle sunshine provide short periods of high irradiance. Existing low light levels in typical commercial hazelnut orchards almost certainly limit primary productivity. Opening the canopy to improve light infiltration could increase the amount or duration of PAR available at leaf level and boost net carbon gain.

Flowering. Although inflo- 
rescence densities were highly variable, shade reduced male and female inflorescence density in hazelnut. The density of female inflorescences (cymules) declined linearly as shade increased in 'Ennis' and 'Barcelona' (Fig. 4 a and b). For 'Ennis,' the decline in mean cymule density was more than one-third between the two most extreme shade treatments (from 18.2 to $11.8 / \mathrm{cm}^{2}$ branch cross-sectional area); mean cymule density was $20 \%$ less than in full sun, even in $30 \%$ shade. 'Barcelona' produced fewer cymules than 'Ennis', but the percentage decline in cymule density with shade was similar in both cultivars.

Average catkin density was similar for 'Barcelona' and 'Ennis' in full sun (Fig. $4 \mathrm{a}$ and b). Shade reduced flower density more severely for male inflorescences (catkins) than for cymules in both cultivars. After one season of $30 \%$ shade, mean catkin density in 'Ennis' fell by $20 \%$, and in $92 \%$ shade, the reduction was $74 \%$ compared to full sun (Fig. 4a). The reduction in catkin density attributable to light exclusion was comparatively less in 'Barcelona', with the most severe shade treatment decreasing catkin density by only about $64 \%$ compared to full sun. All shade treatments reduced catkin density in hazelnut, in contrast to walnut, where shade increases catkin initiation (Ryugo et al., 1985).

The greater depression of male relative to female flower bud formation in shade resulted in a statistically measurable alteration in the sex ratio for 'Ennis'. The average male : female inflorescence ratio on the flagged limbs declined from about unity in full sun to 0.35 in $92 \%$ shade ( $\operatorname{sex}$ ratio $=1.04-0.0078 \mathrm{x}, r^{2}=0.57^{* * * *}$, where $\mathrm{x}=$ percent shade). Sex ratio for 'Barcelona' remained near unity after shading (data not shown).

Flower bud formation seems to be much less sensitive to shade in hazelnut than in other orchard crops. Continuous $92 \%$ shade reduced

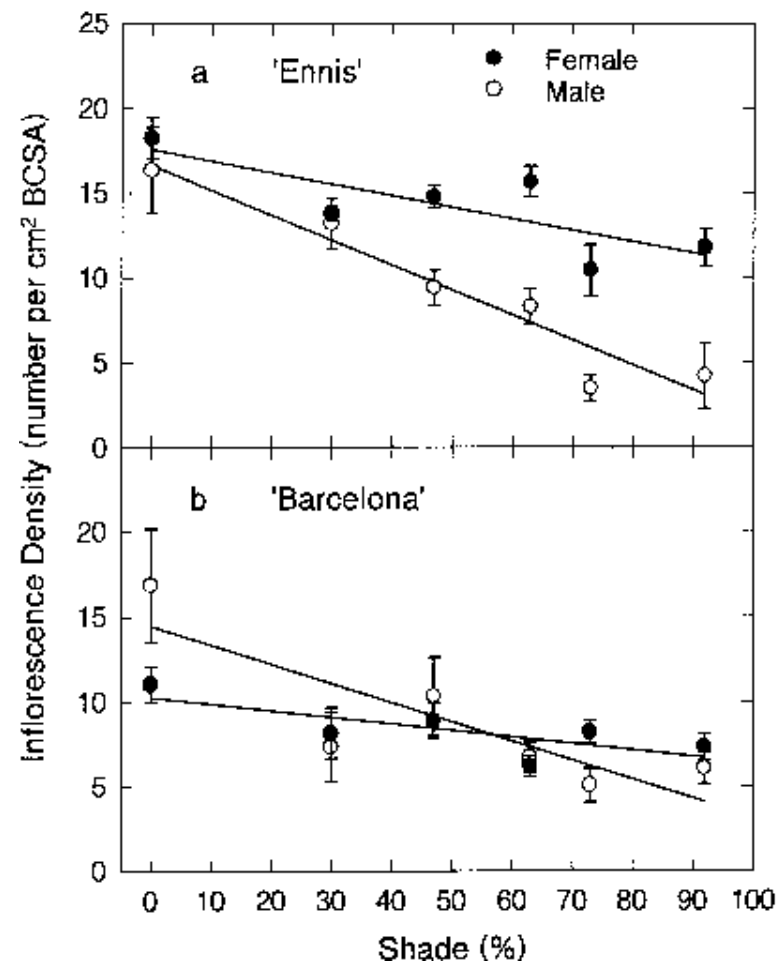

Fig. 4. Inflorescence density declines as canopy illumination declines for male and female inflorescences of (a) 'Ennis' and (b) 'Barcelona.' BCSA = branch cross-sectionalarea. Verticalbars representstandarderrors. Regression equations were as follows (where $\mathrm{x}=$ percent shade): 'Ennis' , cymules $/ \mathrm{cm}^{2}$ $\mathrm{BCSA}=17.56-0.068 \mathrm{x}, r^{2}=0.42^{* * * *}$; 'Ennis', catkins $/ \mathrm{cm}^{2}=16.65-0.15 \mathrm{x}$, $r^{2}=0.68^{* * *}$; 'Barcelona' cymules $/ \mathrm{cm}^{2}=10.25-0.038 \mathrm{x}, r^{2}=0.26^{* *}$; 'Barcelona' catkins $/ \mathrm{cm}^{2}=14.45-0.11 \mathrm{x}, r^{2}=0.42^{* * *}$. cymule density by $<40 \%$. Return bloom on self-shaded walnut spurs was $26 \%$ for bearing or $53 \%$ for nonbearing spurs (Ryugo et al., 1980). Kiwifruit subjected to continuous $70 \%$ shade before the end of July did not flower at all the next year (Fabbri et al., 1992). Peach under $91 \%$ shade from mid-June to late September had flower densities only $9 \%$ of control values (Marini and Sowers, 1990).

Hazelnuts are self-incompatible, so a reduction in catkin density in the main cultivar in an orchard is not of great concern, especially because pollen is produced in excess in this anemophilous species. Low catkin production may still affect yield potential, however. Cymules are borne on stems and on catkin peduncles. In evaluating the flowering habit of advanced selections from the Oregon State Univ. hazelnut breeding program, Azarenko and McCluskey (unpublished data) have found that the best-yielding genotypes set well on stem-borne cymules and those borne on catkin peduncles. If there were fewer catkins, there would presumably be fewer sites for cymules as well. Thus, the differential effect of shade on male and female inflorescence density implies that the yield potential of cultivars that set well on catkin-peduncle cymules (e.g., 'Ennis') may be affected more than those that set primarily on stem flowers (e.g., 'Barcelona').

Nut yield and quality. Yield per tree and yield efficiency ( $\mathrm{YE}=$ $\mathrm{kg} \cdot \mathrm{cm}^{-2}$ trunk cross-sectional area) were strongly reduced by shade for both cultivars and in both years for 'Ennis' (Fig. 5). Yield per tree declined quadratically in 'Ennis' and linearly in 'Barcelona'. In the first year of shade, 'Ennis' yielded $45 \%$ less on average in $30 \%$ shade than in full sun and $82 \%$ less in $92 \%$ shade. The observed decline in yield efficiency (Fig. 5b) suggests that shade is more detrimental to yield than to vegetative growth (as measured by trunk girth).

The reduction in in-shell weight per nut with shade for 'Ennis' was

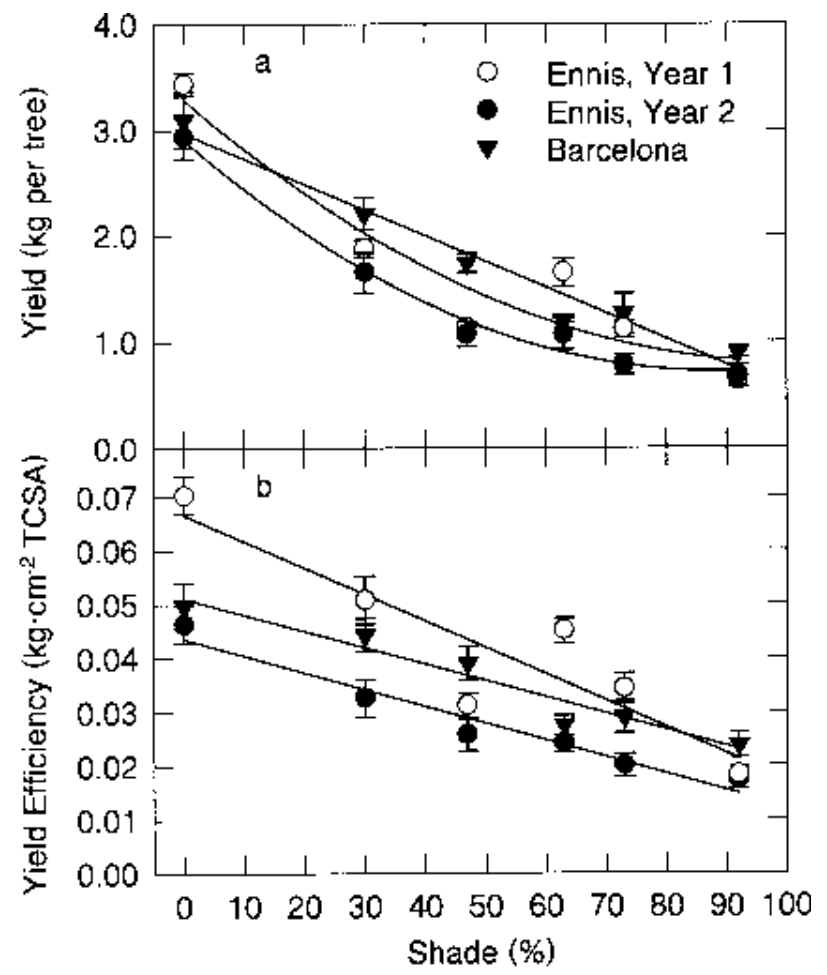

Fig. 5. Shade reduces (a) yield per tree and (b) yield efficiency (YE) in 'Ennis' and 'Barcelona.' TCSA = trunk cross-sectional area. Vertical bars represent standard errors. Regression equations (where $\mathrm{x}=$ percent shade) were as follows: 'Ennis' year 1 , yield $=3.29-0.050 \mathrm{x}+0.00025 \mathrm{x}^{2}, r^{2}=0.85^{* * *}$; 'Ennis' year 2 , yield $=2.91-0.050 \mathrm{x}$ $+0.00028 \mathrm{x}^{2}, r^{2}=0.89^{* * *} ;$ 'Barcelona' yield $=2.97-0.024 \mathrm{x}, r^{2}=0.86^{* * *}$; 'Ennis' year $1, \mathrm{YE}=0.066-0.00049 \mathrm{x}, r^{2}=0.73^{* * *}$; 'Ennis' year 2, $\mathrm{YE}=0.043-0.00031 \mathrm{x}, r^{2}=$ $0.76^{* * * *}$; 'Barcelona' $\mathrm{YE}=0.051-0.00031 \mathrm{x}, r^{2}=0.72^{* * *}$. 
quadratic the first year and linear the second and for 'Barcelona' was linear (Fig. 6a). The difference in weight per nut between cultivars reflects the larger nut size of 'Ennis.' The relative reduction in 'Barcelona' nut weight in $92 \%$ shade (26\%) was similar to that found in year 2 for 'Ennis.' Shade reduced nut weight slightly in walnut (Ryugo et al., 1980). Shade also reduced the weight of kiwifruit and apple; heavy shade for 2 years virtually eliminated cropping in apple (Jackson and Palmer, 1977; Snelgar et al., 1992).

Average nut weight was higher in the second year of shading than in the first for 'Ennis.' The difference probably arises from a combination of factors, including weather differences between the 2 years and adjustment of crop load to resource availability in the second year. After the first year of shade, fewer flowers were produced. If this resulted in fewer nuts, the constraints on bringing those nuts to normal size would have been less severe because of reduced competition between nuts.

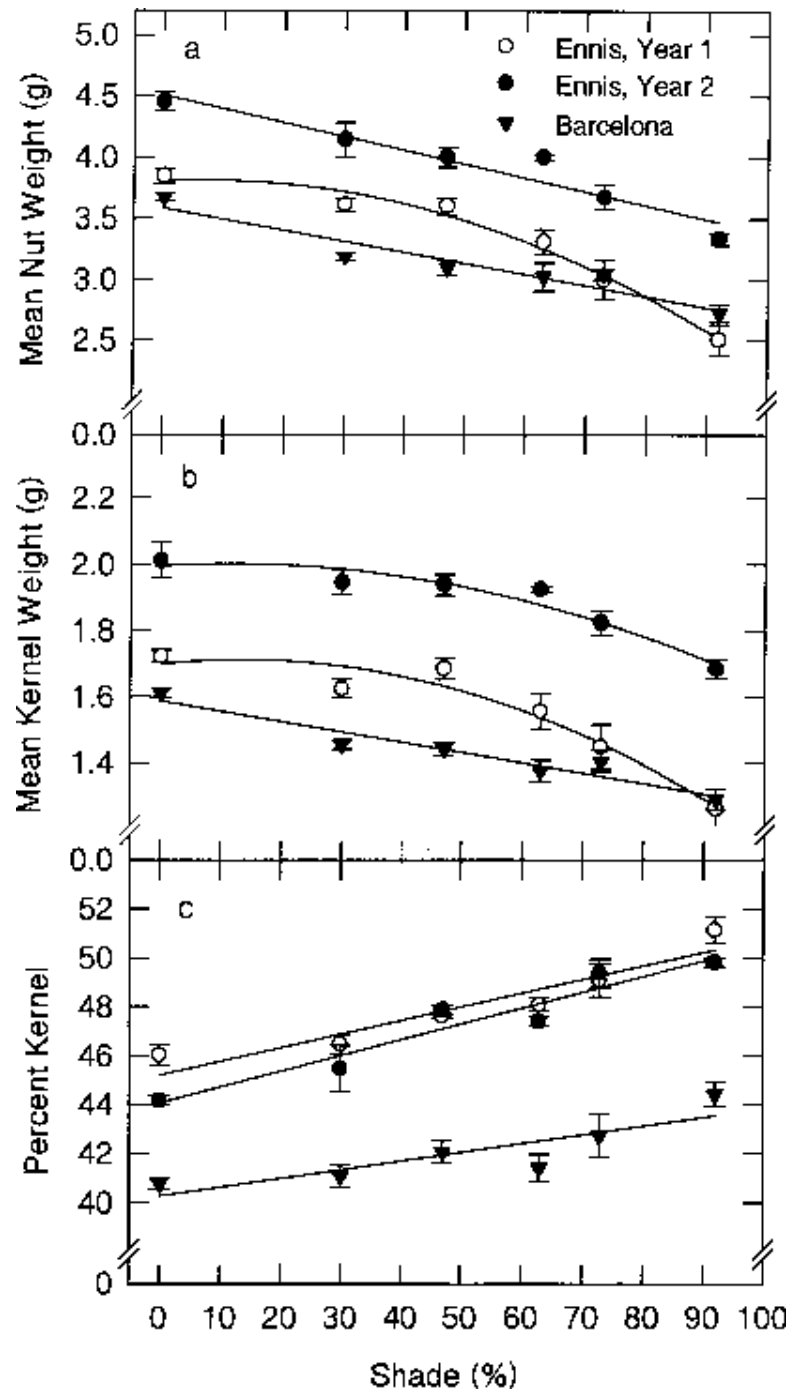

Fig. 6. The influence of increasing shade on (a) mean individual nut weight (b) mean kernel weight (c) percent kernel of 'Ennis' and 'Barcelona' hazelnuts. Vertical bars represent standard errors. Regression equations (where $\mathrm{x}=$ percent shade): 'Ennis' year 1, nut weight $=3.81+0.0026 \mathrm{x}-0.00018 \mathrm{x}^{2}, r^{2}$ $=0.84^{* * * *}$; 'Ennis' year 2 , nut weight $=4.51-0.011 \mathrm{x}, r^{2}=0.77^{* * *}$; 'Barcelona,' nut weight $=3.58-0.0090 \mathrm{x}, r^{2}=0.79^{* * *}$; 'Ennis' year 1 , kernel weight $=1.70$ $+0.0020 \mathrm{x}-0.0000073 \mathrm{x}^{2}, r^{2}=0.73^{* * * *}$; 'Ennis' year 2, kernel weight $=2.00+$ $0.0010 \mathrm{x}-0.000046 \mathrm{x}^{2}, r^{2}=0.71^{* * * *}$; 'Barcelona,' kernel weight $=1.59-$ $0.0031 \mathrm{x}, r^{2}=0.76^{* * * *}$; 'Ennis' year 1, percent kernel $=45.2+0.056 \mathrm{x}, r^{2}=$ $0.74^{* * *}$; 'Ennis' year 2 , percent kernel $=44.1+0.064 \mathrm{x}, r^{2}=0.79^{* * *}$; 'Barcelona,' percent kernel $=40.3+0.035 \mathrm{x}, r^{2}=0.47^{* * * *}$.
Comparison of in-shell nut weight does not account for changes in shell thickness or differences in the incidence of blanks or poorly filled kernels. Kernels were therefore evaluated. Kernel weight was a stable characteristic in both cultivars: the coefficient of variation among trees within a treatment was typically $<5 \%$. Shade had little effect (a reduction of $15 \%$ or less) on kernel weight except in the one or two most severe shade treatments in 'Ennis' (Fig. 6b). Because shade influenced nut weight more than kernel weight, the percent kernel increased slightly (Fig. 6c). Shell thickness and the proportion of the nut cavity filled by the kernel were noticeably affected. Shell thickness was not measured, but kernels with poor fill were counted as defects.

The types and proportions of nut defects varied with cultivar and year but some trends emerged. The percentage of poorly filled nuts and moldy kernels increased as shade increased, and the incidence of blanks (nuts without kernels) decreased. These defects were the most prevalent in 'Ennis' (Fig. 7 a and b). Odds ratios (relative to 0\% shade) and logistic regression equations for the incidence of various nut defects appear in Hampson (1995). The odds of finding a blank were approximately halved in $92 \%$ shade compared to full sun for both cultivars. The proportion of defects was much higher in 'Barcelona'; blanks and poorly filled nuts were the most common (Fig. 7c). The incidence of blanks was near $20 \%$ for 'Barcelona' in all but the two most shaded treatments. The high incidence of blanks in this clone has been attributed to the fact that it is a translocation heterozygote (Salesses and Bonnet, 1988). Doubles were also more common in 'Barcelona' than 'Ennis,' comprising 1\% to $3 \%$ of the nuts. Fortyfive percent of the 'Barcelona' nuts were defective in some respect under $92 \%$ shade (Fig. 7c).

One defect not quantified was a peculiarity in the shells of

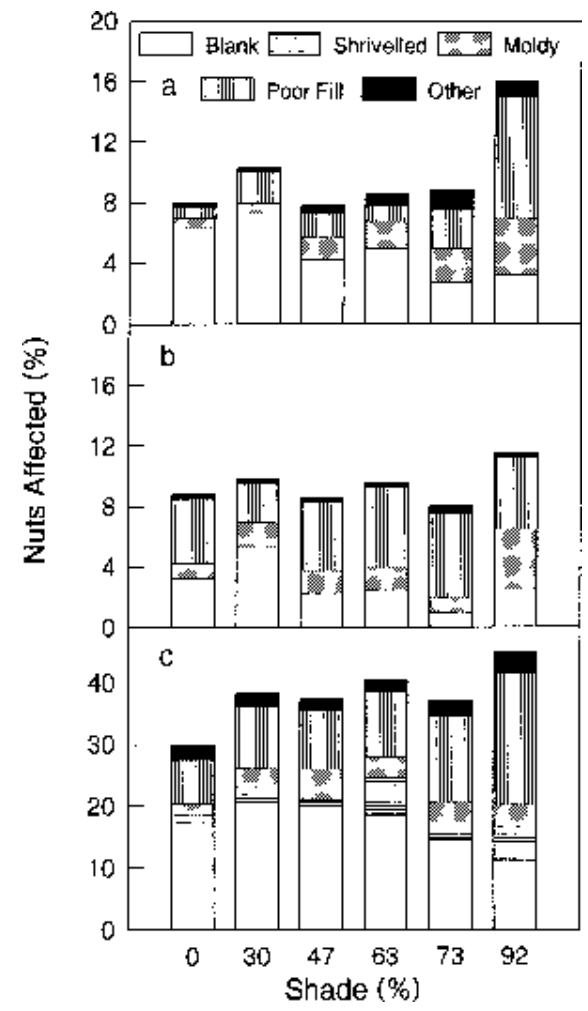

Fig. 7. Types and proportions of nut quality defects in (a) 'Ennis,' year 1 (b) 'Ennis,' year 2 and (c) 'Barcelona' in different light regimes. Note the change in scale on the y-axis for 'Barcelona.' Numbers represent the means of 100-nut samples from four replicate trees. 


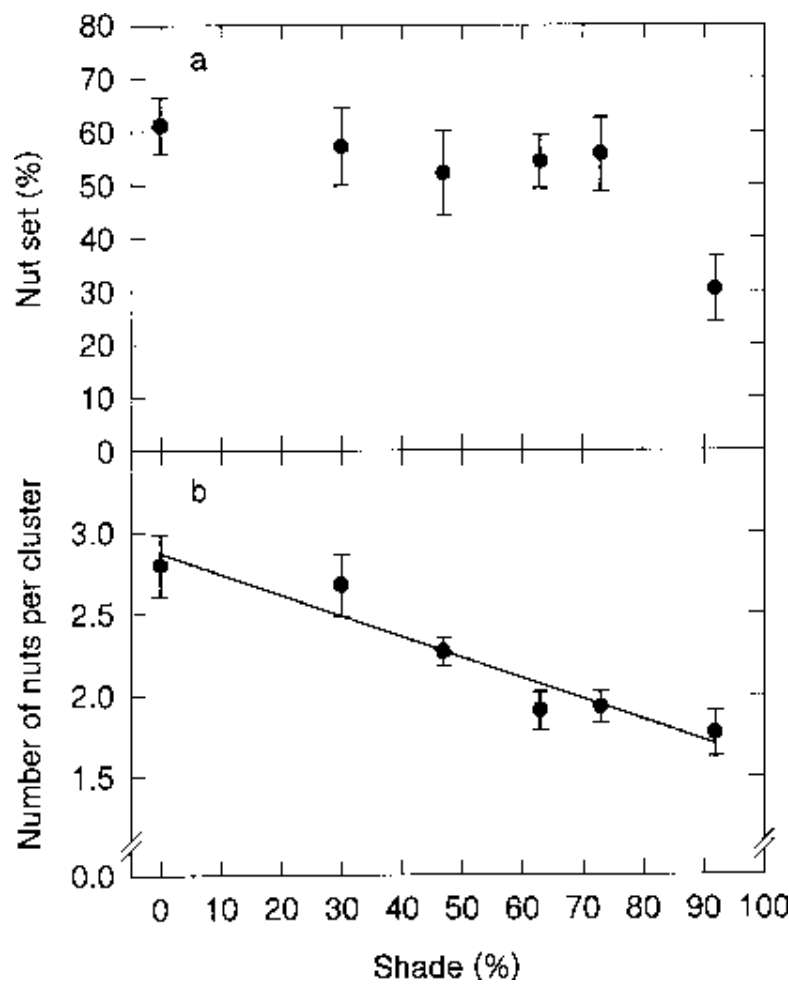

Fig. 8. (a) Nut set and (b) the number of nuts per cluster in 'Barcelona' decline in the shade. Vertical bars represent standard errors. Nut set (\%) $=($ no. of nut clusters $/$ no of nodes bearing cymules $) \times 100$. Nut set $(\%)$ $=64.58-0.25 \mathrm{x}, r^{2}=0.25^{*}$; nuts per cluster $=2.87-0.013 \mathrm{x}, r^{2}=0.66^{* * *}$, where $\mathrm{x}=$ percent shade

'Ennis' nuts. A darkened constriction around the nut was frequently seen in nuts from trees in $73 \%$ or $92 \%$ shade. The shell in this zone was very thin, but the kernels were not necessarily misshapen. This defect did not occur in 'Barcelona.'

Yield components. Yield components in hazelnut include cymule density, nut set, number of nuts per cluster, and nut weight. Flower densities were assumed to be equal among the 'Ennis' trees before the shading experiment, because all trees grew in full sunlight in previous years. The yield reductions in the first season were therefore inferred to arise from a combination of low nut set and reduced nut weight, because 'Ennis' sets nearly all single-nut clusters.

The relationship among yield components was examined in 'Barcelona' to find the components most sensitive to shade. Cymule densities were measured the year before shading and did not differ significantly among trees $(P=0.31)$. After 1 year of shade, nut density on the flagged limbs underwent a linear decline with increasing shade (number of nuts per square centimeter branch cross-sectional area $=23.6-0.15 \mathrm{x}, r^{2}=0.49^{* * *}$ ), mirroring the reduction in yield efficiency on the whole trees (Fig. 5b).
'Barcelona' responded to shade by altering the number of nuts per cluster more than nut set; the latter declined noticeably only in $92 \%$ shade (Fig. 8).

Calculations of predicted yields based on treatment means for cymule density, nut set, number of nuts per cluster, and nut weight indicated that reductions in measured yield components were sufficient to account for the yield loss observed in 'Barcelona.' For example, in $30 \%$ shade, estimated yield as a fraction of control trees was calculated as cymule density $\times$ nut set $\times$ nuts per cluster $\times$ nut weight, to obtain $1.0 \times 0.93 \times 0.95 \times 0.87=0.77$, and actual yield was $0.72 \times$ control (Table 3 ). Approximations were also fairly close for the other light regimes (Table 3 ).

Yield reduction under slight to moderate shade therefore seems to be caused mainly by a decrease in nut number in the first year of shading, although some decrease in nut weight also occurred. The two cultivars adjusted nut number in different ways. 'Ennis' almost certainly adjusted nut number by decreasing nut set, and 'Barcelona' produced fewer nuts per cluster.

To quantify how different degrees of shade influence reproductive potential, we shaded whole trees. Yield reductions in an orchard would never be as severe as those found here because the top of the tree would always receive full sun. Large losses in yield and reproductive potential (inflorescence density, nut set, etc.) are, however, likely in lower portions of the canopy (self-shading) and wherever the canopy is shaded by adjacent rows or adjacent trees within a row.

\section{Conclusion}

The evidence presented here suggests that the low PAR in the canopy under current pruning practices is more likely to affect yield than flower bud formation in hazelnut. Yield was more sensitive to shade than flowering: in the mildest $(30 \%)$ shade regime, mean yield dropped by up to $45 \%$, while cymule density dropped only about $20 \%$. Fruiting wood probably experiences more shade than the wood initiating flower buds (the current year's growth), because attenuation of PAR is very rapid with depth in the canopy. In addition, the presence of a critical period cannot be discounted. This study did not attempt to define the effect of timing or duration of shade on reproduction. Between May and July, floral initiation (both sexes), vigorous vegetative growth, fertilization, nut set, and the onset of rapid nut enlargement all compete for photosynthate. Possibly nut set is a critical time for avoiding shade-induced photosynthate deficiency. Failure of fertilization represents an irreversible loss in nut numbers, whereas vegetative growth or nut weight may be affected incrementally, with potential for compensation later if the deficiency were ameliorated. Further experiments would be needed to identify any possible critical stages or yield compensation opportunities.

We believe that canopy management merits more attention in hazelnut. Because flowering in hazelnut is less sensitive to shade and fruit color is not an issue, canopy management would not need

Table 3. Predicted and actual yields for shaded 'Barcelona' trees, based on treatment means for yield components as a fraction of control (unshaded) trees.

\begin{tabular}{lcccccc}
\hline \hline $\begin{array}{l}\text { Shade } \\
(\%)\end{array}$ & $\begin{array}{c}\text { Cymule } \\
\text { density }\end{array}$ & $\begin{array}{c}\text { Nut } \\
\text { set }\end{array}$ & $\begin{array}{c}\text { Nuts/ } \\
\text { cluster }\end{array}$ & $\begin{array}{c}\text { Nut } \\
\text { wt }\end{array}$ & $\begin{array}{c}\text { Predicted } \\
\text { yield }\end{array}$ & $\begin{array}{c}\text { Actual } \\
\text { yield }\end{array}$ \\
\hline 30 & 1.00 & 0.93 & 0.95 & 0.87 & 0.77 & 0.71 \\
47 & 1.00 & 0.85 & 0.81 & 0.84 & 0.58 & 0.56 \\
63 & 1.00 & 0.89 & 0.68 & 0.82 & 0.50 & 0.39 \\
73 & 1.00 & 0.91 & 0.67 & 0.83 & 0.52 & 0.41 \\
92 & 1.00 & 0.49 & 0.63 & 0.74 & 0.23 & 0.29 \\
\hline
\end{tabular}


to be as intensive as in apple. Consideration of the data suggests that, for best yield and nut quality, the previous year's [fruiting] wood should be in no more than about $50 \%$ shade. Current growth would also then be in a favorable light environment for adequate floral initiation. While photosynthesis is light-saturated in individual leaves at $40 \%$ to $50 \%$ full sun, the canopy as a whole probably is not. Opening the canopy to improve infiltration of sunlight would likely increase net carbon fixation by taking advantage of the photosynthetic capacity of a greater proportion of the leaves. Future experiments could explore the feasibility of maintaining $50 \%$ shade or less in the fruiting zone under orchard conditions.

\section{Literature Cited}

Arnon, D.I. 1949. Copper enzymes in isolated chloroplasts. Polyphenoloxidase in Beta vulgaris. Plant Physiol. 24:1-15.

Bassman, J.H. and J.C. Zwier. 1991. Gas exchange characteristics of Populus trichocarpa, Populus deltoides and Populus trichocarpa $\times$ P. deltoides clones. Tree Physiol. 8:145-159.

Boardman, N.K. 1977. Comparative photosynthesis of sun and shade plants. Ann. Rev. Plant Physiol. 28:355-377.

Campbell, R.J., R.P. Marini, and J.B. Birch. 1992. Canopy position affects light response curves for gas exchange characteristics of apple spur leaves. J. Amer. Soc. Hort. Sci. 117:467-472.

Crews, C.E., R.E. Worley, J.P. Syvertsen, and M.G. Bausher. 1980. Carboxylase activity and seasonal changes in $\mathrm{CO}_{2}$ assimilation rates in three cultivars of pecan. J. Amer. Soc. Hort. Sci. 105:798-801.

DeJong, T.M. 1983. $\mathrm{CO}_{2}$ assimilation characteristics of five Prunus tree fruit species. J. Amer. Soc. Hort. Sci. 108:303-307.

Fabbri, A., M. Lisetti, and C. Benelli. 1992. Studies on flower induction in kiwifruit. Acta Hort. 297 (Vol. 1):217-222.

Faust, M. 1989. Physiology of temperate zone fruit trees. Wiley, New York.

Hampson, C.R. 1995. Aspects of flowering in hazelnut: self-incompatibility and light requirement. PhD diss., Oregon State Univ., Corvallis.

Harbinson, J. and F.I. Woodward. 1984. Field measurements of the gas exchange of woody plant species in simulated sunflecks. Ann. Bot. 53:841-851.

Higgins, S.S., F.E. Larsen, R.B. Bendel, G.K. Radamaker, J.H. Bassman, W.R. Bidlake, and A. Al Wir. 1992. Comparative gas exchange characteristics of potted, greenhouse-grown almond, apple, fig, grape, olive, peach and Asian pear. Scientia Hort. 52:313-329.

Jackson, J.E. 1980. Light interception and utilization by orchard systems. Hort. Rev. 2:208-267.

Jackson, J.E. and J.W. Palmer. 1977. Effects of shade on the growth and cropping of apple trees. II. Effects on components of yield. J. Hort. Sci. 52:253-266.

Jona, R. 1985. Corylus, p. 333-340. In: A.H. Halevy (ed.). CRC handbook of flowering. vol. 2. CRC Press, Boca Raton, Fla.

Kappel, F. and J.A. Flore. 1983. Effect of shade on photosynthesis, specific leaf weight, leaf chlorophyll content, and morphology of young peach trees. J. Amer. Soc. Hort. Sci. 108:541-544.
Kull, O. and Ü. Niinemets. 1993. Variations in leaf morphometry and nitrogen concentration in Betula pendula Roth., Corylus avellana L. and Lonicera xylosteum L. Tree Physiol. 12:311-318.

Lee, D.W. 1985. Duplicating foliage shade for research on plant development. HortScience 20:116-118.

Lin, T.-S., J.C. Crane, K. Ryugo, V.S. Polito, and T.M. DeJong. 1984. Comparative study of leaf morphology, photosynthesis, and leaf conductance in selected Pistacia species. J. Amer. Soc. Hort. Sci. 109:325-330.

Logan, K.T. 1970. Adaptations of the photosynthetic apparatus of sunand shade-grown yellow birch (Betula alleghaniensis Britt.). Can. J. Bot. 48:1681-1688.

Marini, R.P. 1986. Do net gas exchange rates of green and red peach leaves differ? HortScience 21:118-120.

Marini, R.P. and D.L. Sowers. 1990. Net photosynthesis, specific leaf weight, and flowering of peach as influenced by shade. HortScience 25:331-334.

Nobel, P.S. 1983. Biophysical plant physiology and ecology. W.H. Freeman, New York.

Pezeshki, S.R. and T.M. Hinckley. 1982. The stomatal response of red alder and black cottonwood to changing water status. Can. J. For. Res. 12:761-771.

Proctor, J.T.A. 1981. Stomatal conductance in leaves of McIntosh apple trees before and after fruit removal. Can. J. Bot. 59:50-53.

Ranney, T.G., R.E. Bir, and W.A. Skroch. 1991. Comparative drought resistance among six species of birch (Betula): Influence of mild water stress on water relations and leaf gas exchange. Tree Physiol. 8:351360.

Ryugo, K., G. Bartolini, R.M. Carlson, and D.E. Ramos. 1985. Relationship between catkin development and cropping in the Persian walnut 'Serr.' HortScience 20:1094-1096.

Ryugo, K., B. Marangoni, and D.E. Ramos. 1980. Light intensity and fruiting effects on carbohydrate contents, spur development, and return bloom of 'Hartley' walnut. J. Amer. Soc. Hort. Sci. 105:223-227.

Salesses, G. and A. Bonnet. 1988. Etude cytogénétique d'hybrides entre variéties de noisetier (Corylus avellana) porteuses d'une translocation à l'état hétérozygote. Cytologia 53:407-413.

Schulze, E.-D. and M. Küppers. 1979. Short-term and long-term effects of plant water deficits on stomatal response to humidity in Corylus avellana L. Planta 146:319-326.

Snelgar, W.P., P.J. Manson, and P.J. Martin. 1992. Influence of time of shading on flowering and yield of kiwifruit vines. J. Hort. Sci. 67:481487.

Tombesi, A., T.M. DeJong, and K. Ryugo. 1983. Net $\mathrm{CO}_{2}$ assimilation characteristics of walnut leaves under field and laboratory conditions. J. Amer. Soc. Hort. Sci. 108:558-561.

Turner, N.C., E.-D. Schulze, and T. Gollan. 1984. The responses of stomata and leaf gas exchange to vapour pressure deficits and soil water content. I. Species comparisons at high soil water contents. Oecologia 63:338-342.

United States Department of Agriculture. 1993. Fruit and tree nuts situation and outlook. Commodity Econ. Div., Econ. Res. Serv., U.S. Dept. of Agr. TFS-265.

Westwood, M.N. 1993. Temperate zone pomology: Physiology and culture. 3rd ed. Timber Press, Portland, Ore. 